\title{
Structural Capacity Analysis of Corroded Steel Girder Bridges
}

\author{
Amanda Bao, Michael Gulasey, Caleb Guillaume, Nadezhda Levitova, Alana Moraes, Christopher Satter \\ Civil Engineering Technology, College of Applied Science and Technology, Rochester Institute of Technology \\ 78 Lomb Memorial Drive, ENT-3154, Rochester, NY 14623, USA \\ axbite@rit.edu
}

\begin{abstract}
More than 9\% of the bridges in the United States were labeled structurally deficient according to the 2017 American Society of Civil Engineers' infrastructure report card. The main causes of bridge deterioration are repeated vehicular loads and adverse environmental exposure. The most dominant deterioration form for steel bridges is corrosion, which is characterized by the loss of metal area resulting in reduction of structural capacity. Corrosion in steel multi-girder bridges is common in cold regions because of the frequent use of deicing chemicals during the winter season as well as leakage caused by bridge joint damage. At times, the rust is serious enough to disconnect the web from the flanges of the girder. This poses significant concerns for load capacity especially at girder ends. The consequences of bridge failure can be disastrous. This research investigates the structural capacity of these corroded steel girders. The mechanical behaviors of deteriorated girders are studied by 3-D finite element models built in ABAQUS and by lab testing. Our analysis is focused on web area loss and web thinning due to corrosion, and their consequences for load capacity reduction. The effects of location, size, and shape of area loss on shear and web buckling resistance will be studied. Lab tests on steel girder models will be conducted to verify the results from finite element modeling. Based on our analysis and findings, a simple and dependable rating method to evaluate deteriorated steel girder bridges will be developed.
\end{abstract}

Keywords: Bridge, Girder, Deterioration, Finite Element.

\section{Introduction}

According to the ASCE 2017 Infrastructure Report Card, New York State received a D+ rating for bridges. ${ }^{[6]}$ More than $9 \%$ of bridges in the United States were labeled structurally deficient, indicating some degree of corrosion or deterioration of structural elements. Corrosion in steel multi-girder bridges is very common in cold regions. This is due to both frequent use of deicing chemicals during the winter season and leakage through the bridge joints. Typical girder corrosion forms are illustrated in Figure 1. Over the years, the rust can be serious enough to disconnect the web from the flanges of the girder, which poses significant concerns for load resistance especially at girder ends. The consequences of bridge failure can be disastrous. 

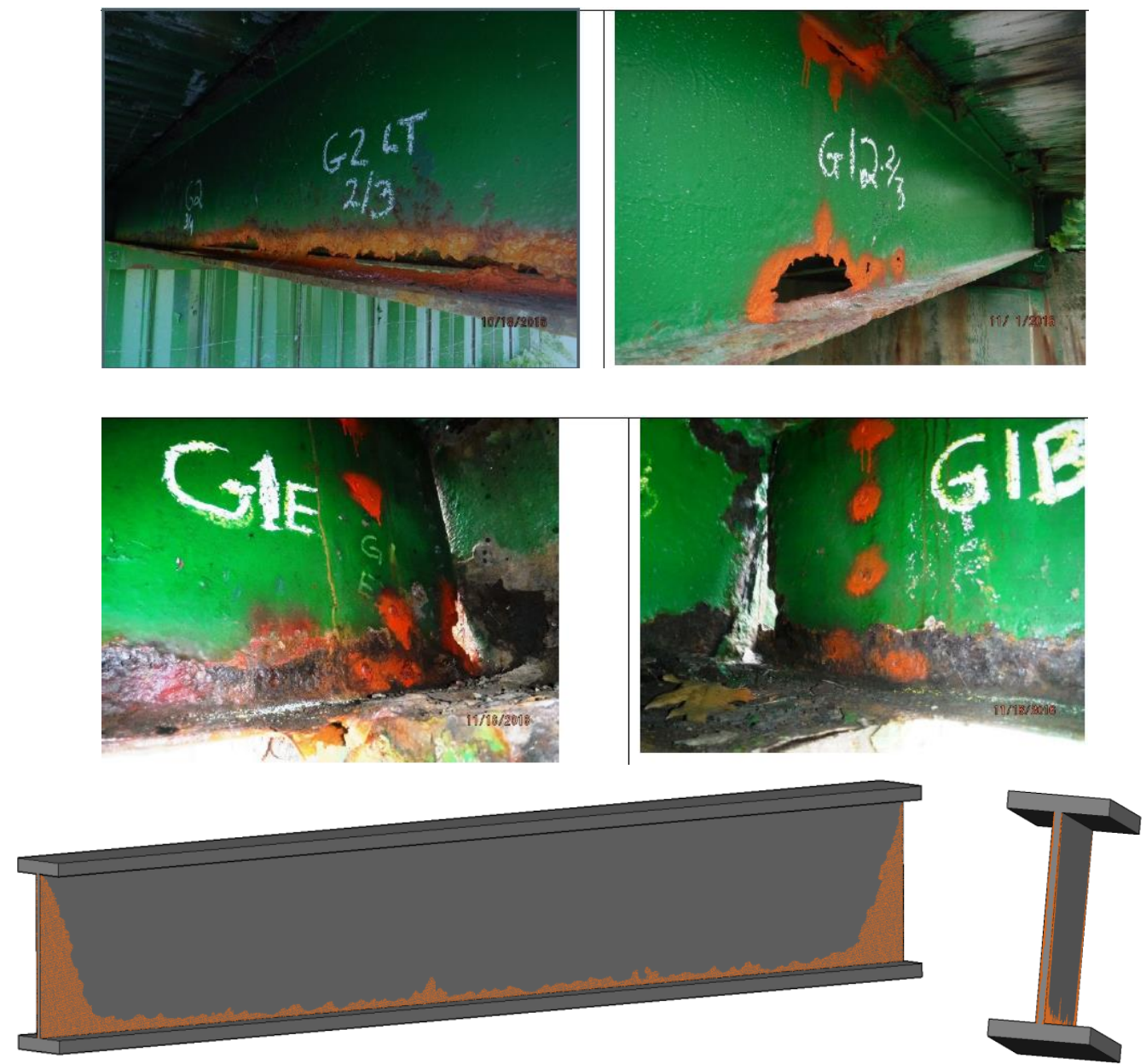

Fig. 1: Typical Steel Girder Corrosion at Web and Flange.

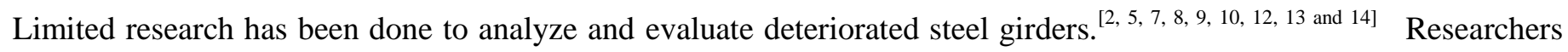
from the City College of New York (Agrawal, A. K. and Kawaguchi, A., 2009) developed deterioration curves and equations using the Weibull-based method to calculate deterioration rates for bridge elements. ${ }^{[2]}$ Ghosn, M., Sivakumar, B. and Miao, F. (2011) developed a Load and Resistance Factor Rating methodology for New York State bridges. ${ }^{[7]}$ Kayser, J. and Nowak, A. (1989) developed a damage model which evaluates the reliability of a corroded steel girder over time. ${ }^{[8]}$ Researchers from Michigan Tech University (Lindt, J. and Ahlborn, T., 2005) developed guidelines for steel beam end deterioration. ${ }^{[14]}$ This paper is built upon these state-of-the art literatures and will advance the current understanding of load capacity analysis of corroded steel girders.

Performing full scale physical experiments on bridges is expensive and sometimes impossible. Consequently, finite element modeling has been adopted in recent decades to conduct research on large scale structures, including bridges. The power of the finite element method lies in its versatility and ability to solve various physical problems. The analyzed domain can have arbitrary shapes, loads, and boundary conditions and the mesh can mix elements of different types, shapes, and material properties. Another attractive feature of the finite element method is the close physical resemblance between the actual structure and its corresponding finite element model. ABAQUS offers powerful and complete solutions for both routine and sophisticated engineering problems covering a vast spectrum of industrial applications including steel structures. ${ }^{[1]}$ In this paper, ABAQUS is used as a numerical tool to study the mechanical behaviors of deteriorated girders.

\section{Finite Element Modeling}

3D finite element models are built to analyze the girder web buckling and shear capacity. The boundary conditions are modeled properly to simulate the real behaviors of supports, such as translation and rotation at the girder ends. The load 
input and the governing load cases are selected according to the load combinations specified in AASHTO LRFD Bridge Design Specifications. $^{[3 \text { and 11] }}$ Area loss will be modeled by removing materials from the web, and web thinning will simulated by uniformly reducing the web thickness. The numerical models resemble real steel corrosion forms by changing the shape, size and location of the area loss. Web thinning due to rust mainly affects the girder's shear strength and web buckling strength. The load capacity of the deteriorated girders is analyzed.

The prototype bridge in this study is a simple span I-Plate steel girder bridge with a cast-in-place concrete deck. The span length of the bridge is 120 feet. The overall width of the bridge is 87 feet, and the bridge carries 6 lanes of traffic. The design live load on the bridge is the typical AASHTO HL-93 Live Load. The cast-in-place deck is 8 inches thick. The bridge framing has 10 girder lines with 9 feet girder spacing. The bridge elevation is shown in Figure 2 and the bridge typical section is shown in Figure 3.

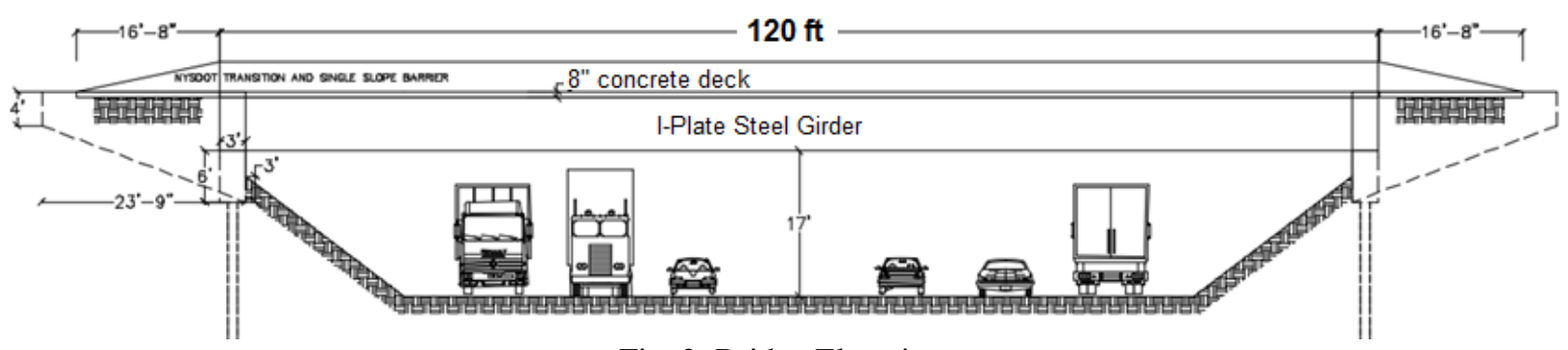

Fig. 2: Bridge Elevation.

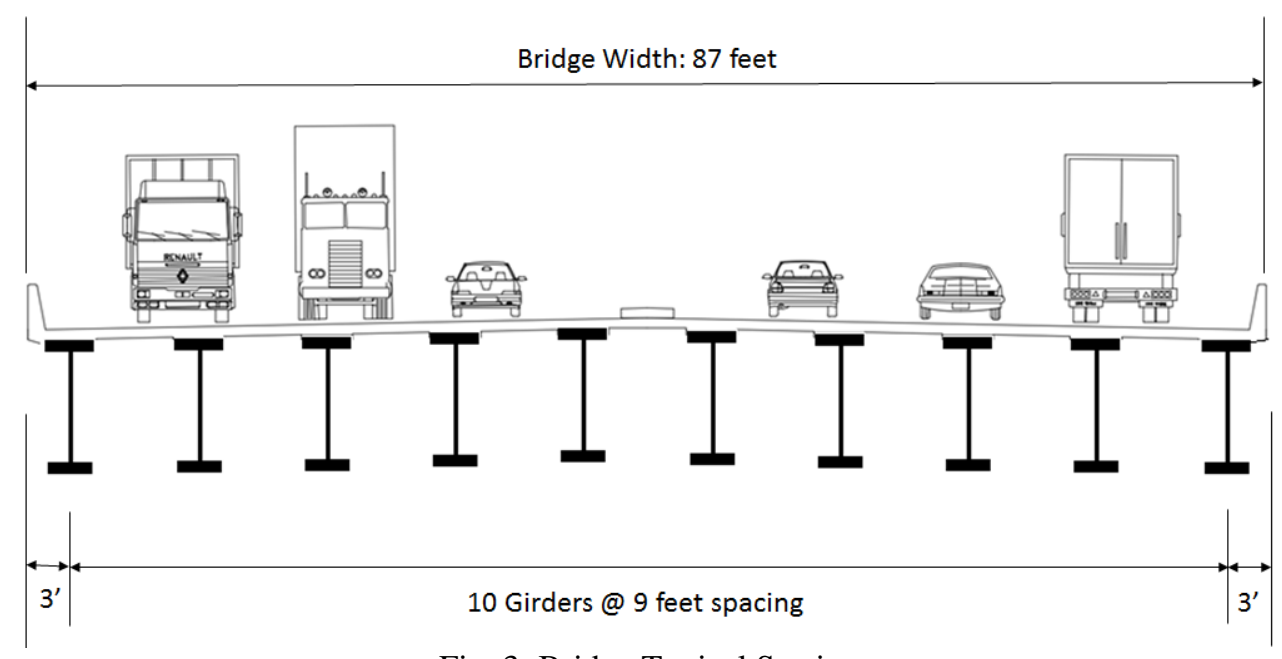

Fig. 3: Bridge Typical Section.

The I-plate steel girder has a top flange of 12 inches wide and 2 inches thick, a web of 48 inches deep and $1 / 2$ inch thick and a bottom flange of 12 inches wide and 2 inches thick. The overall depth of the steel girder is 52 inches. The length of the girder end model is 40 inches. The boundary conditions are pinned at one end of the top and bottom flanges to simulate the real girder end embedded into the abutment diaphragm. The pinned support is 6 inches long on both the top and the bottom flanges to represent the real bearing length of a simple span girder. The other end is free in vertical movement but restricts horizontal movement along the girder line. The 3D finite element model of the girder end is shown in Figure 4. 

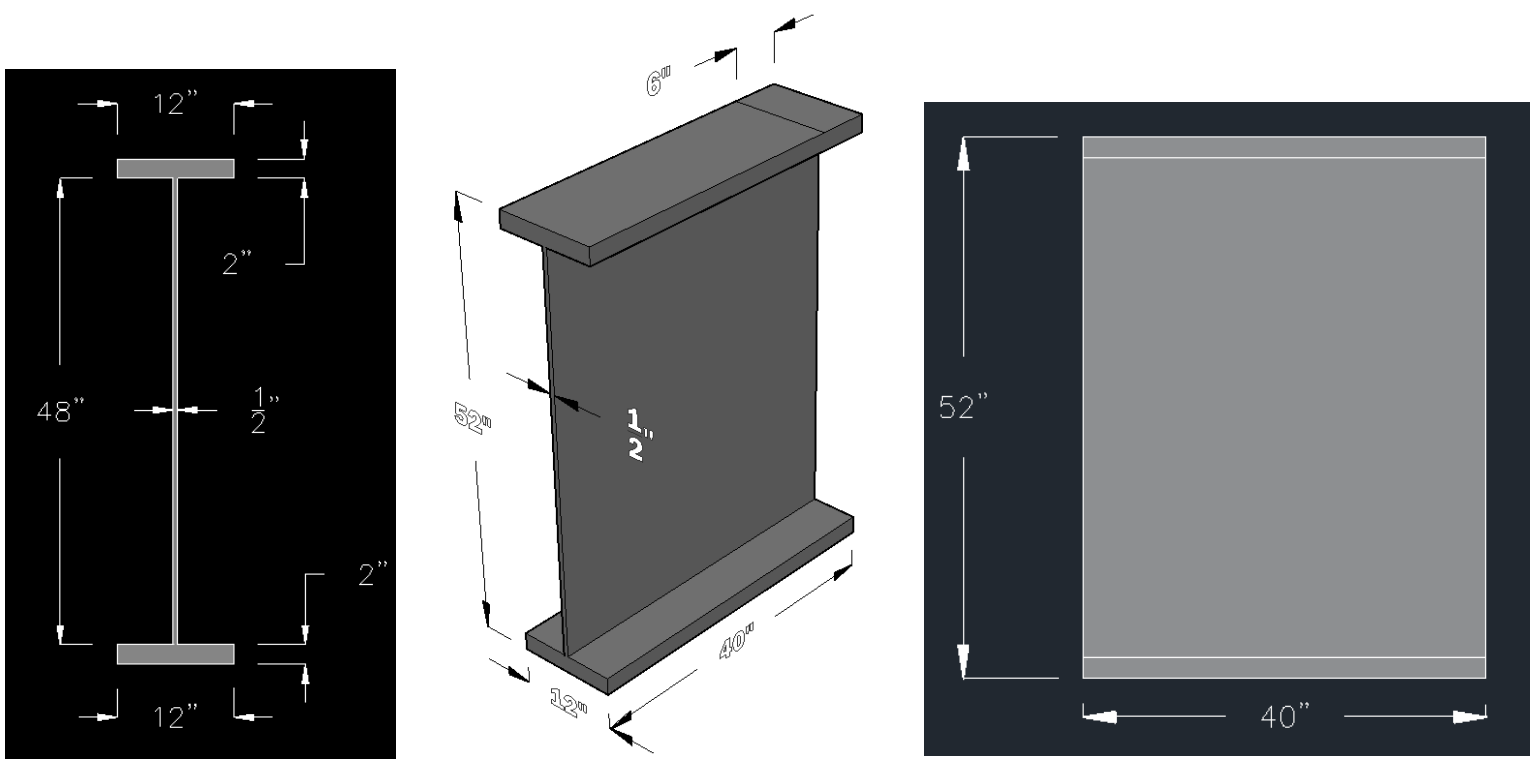

Fig. 4: Dimensions of the Girder End Model.

The steel girder uses ASTM A572 Grade 50 steel, ${ }^{[4]}$ which has a yield strength of $50 \mathrm{ksi}$, and an ultimate strength of $65 \mathrm{ksi}$. The steel has an elastic modulus of 29,000 ksi and a Poisson's ratio of 0.30 .

ABAQUS is used to model two types of girder corrosion are modeled due to rust: area loss and web thinning. The area loss is modeled by removing a part of web area as shown in Figure 5. The effects of different shapes and sizes of area loss on the structural capacity of the girder are investigated. The shapes of area loss are rectangular with the longer side parallel to the girder longitudinal direction, square, and rectangular with the longer side parallel to the web depth. Web thinning is modeled by reducing the thickness of the entire web.
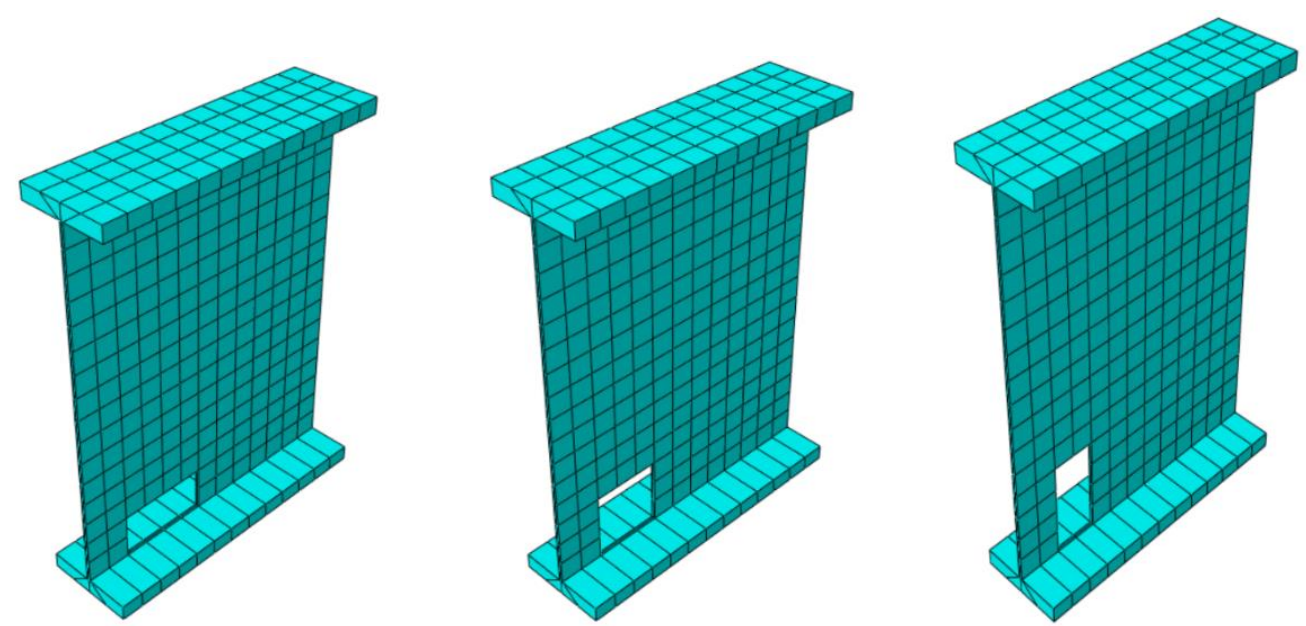

Fig. 5: 3D Finite Element Models of Girder End with Area Loss in ABAQUS.

\section{Results}

In this paper, a typical interior girder is used for calculating the shear force at the girder end. The unfactored non-composite and composite dead load (DC) on the girder is $1.50 \mathrm{kip} / \mathrm{ft}$, and the unfactored wearing surface (DW) on the girder is $0.35 \mathrm{kip} / \mathrm{ft}$. The live load (LL) on the girder is AASHTO HL-93 live load, the dynamic impact factor of the design truck HS20-44 is 1.33, and the live load distribution factor for shear is 0.884 , which is calculated according to AASHTO LRFD Bridge Design Specifications as shown in Equation 1. ${ }^{[3]}$ 
Live load distribution factor for shear $=$

$$
\operatorname{Max}\left\{\begin{array}{c}
\text { one lane loaded: } 0.36+\frac{S}{25}=0.36+\frac{9}{25}=0.720 \\
\geq 2 \text { lanes loaded: } 0.2+\frac{S}{12}-\left(\frac{S}{35}\right)^{2}=0.2+\frac{9}{12}-\left(\frac{9}{35}\right)^{2}=\mathbf{0 . 8 8 4}
\end{array}\right.
$$

where $\mathrm{S}=$ girder spacing.

The maximum design shear force at the girder end is obtained by Strength I load combination specified in Equation 2 according to AASHTO LRFD Bridge Design Specifications. ${ }^{[3]}$

$$
\text { Strength I Load Combination: } 1.25 D C+1.5 D W+1.75 L L
$$

Figure 6 shows the load diagram for the single girder analysis.

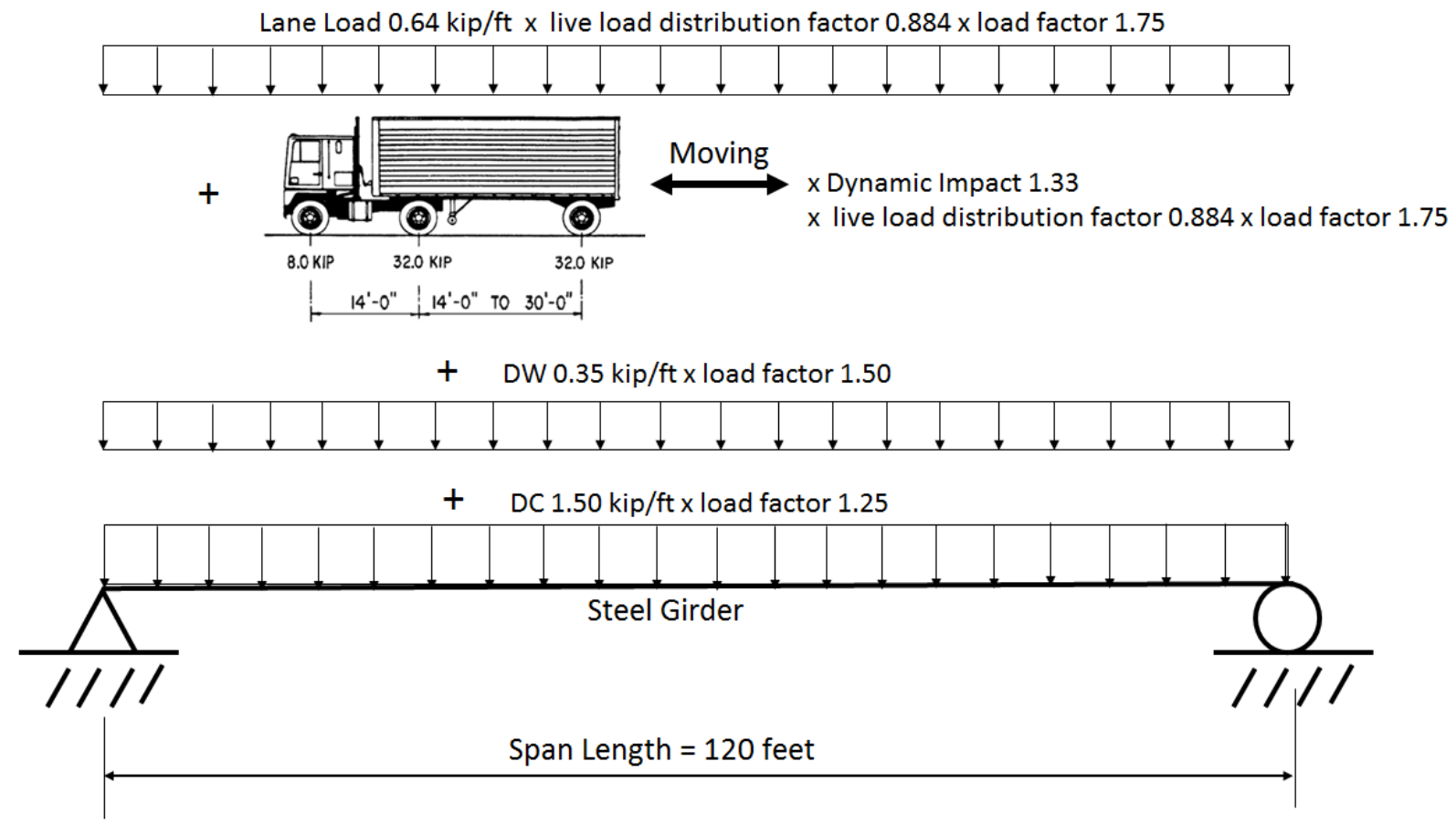

Fig. 6: Load Diagram for Single Girder Analysis.

The calculated design shear force according to the single girder analysis is 340 kips at the girder end.

The original web size is 48 inches deep by $1 / 2$ inch thick. The web thinning due to corrosion is modeled by reducing the web thickness in the section geometry input. The web bucking capacity of the intact web is 447 kips according to the ABAQUS output. The web bucking capacity vs. web thinning is plotted in Figure 7. The web thicknesses in the plot are 0.50 inch (original thickness), 0.475 inch (5\% thickness reduction), 0.45 inch ( $10 \%$ thickness reduction), 0.425 inch ( $15 \%$ thickness reduction), 0.40 inch (20\% thickness reduction), 0.375 inch (25\% thickness reduction) and 0.35 inch (30\% thickness reduction), respectively. 

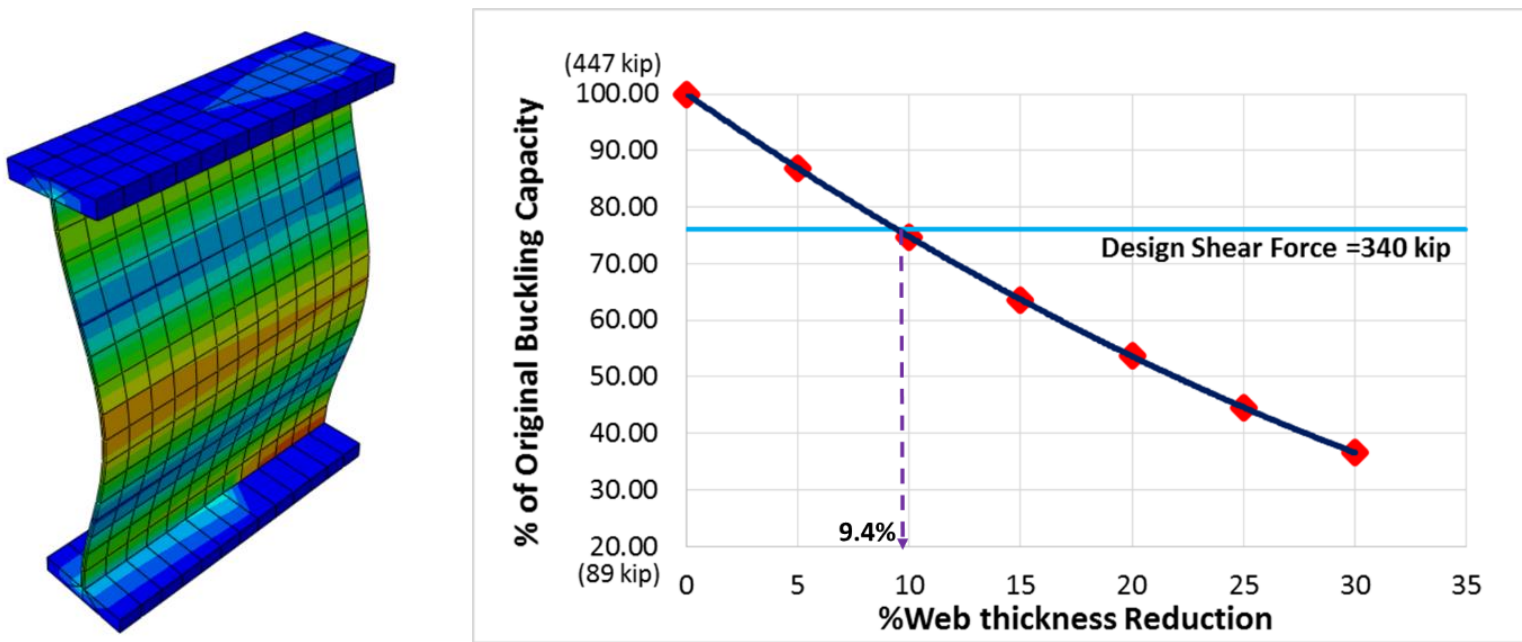

Fig. 7: Web Buckling Capacity vs. Web Thinning.

The area loss due to corrosion is modeled by removing portions of the web. In this study, the shapes of the area loss include rectangles with the longer side parallel to girder line, rectangles with longer side parallel to the web depth, and squares. The results of web buckling capacity vs. different shapes and sizes of area loss are shown in Figure 8, Figure 9 and Figure 10.

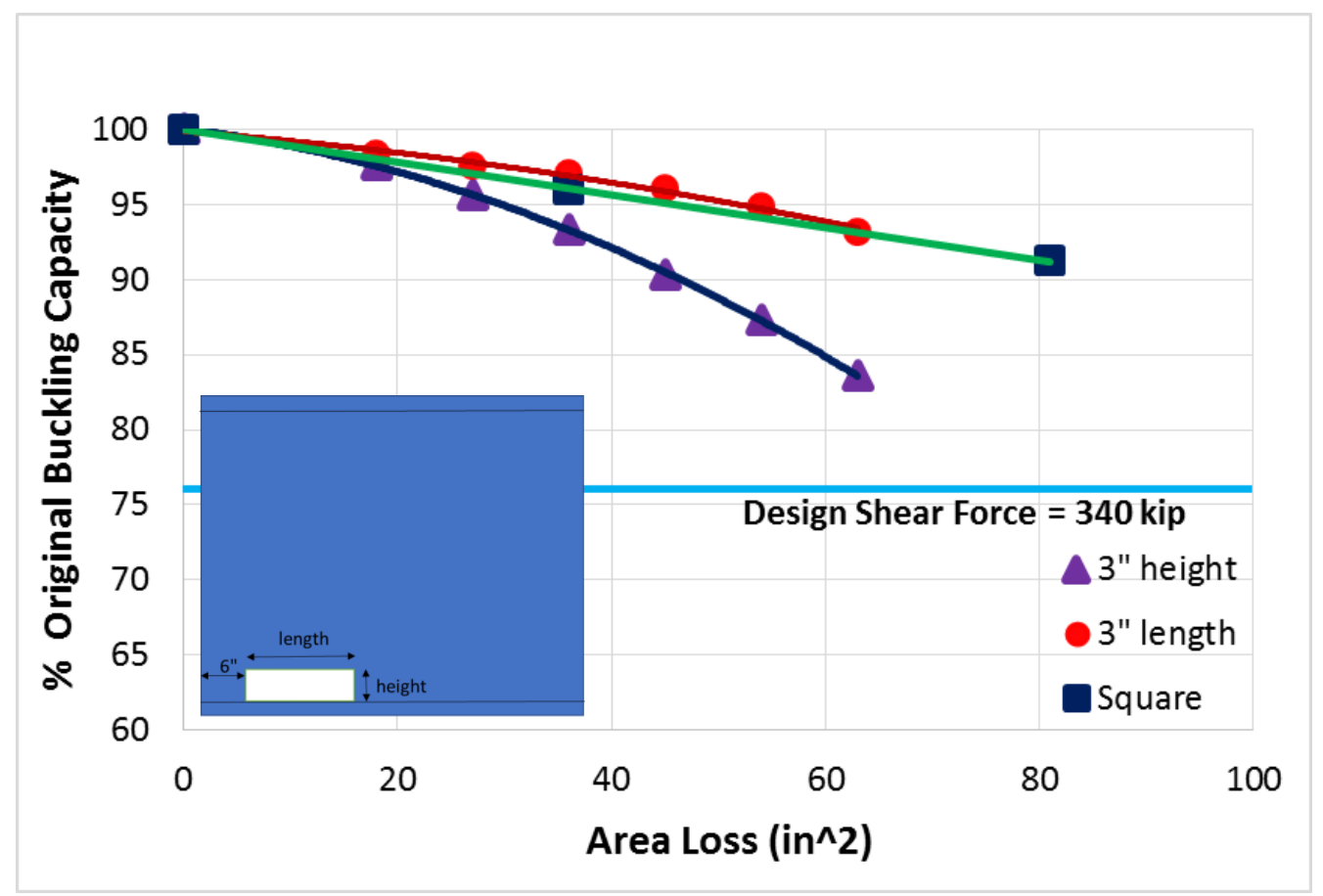

Fig. 8: Web Buckling Capacity vs. Area Loss - Shapes and Sizes. 


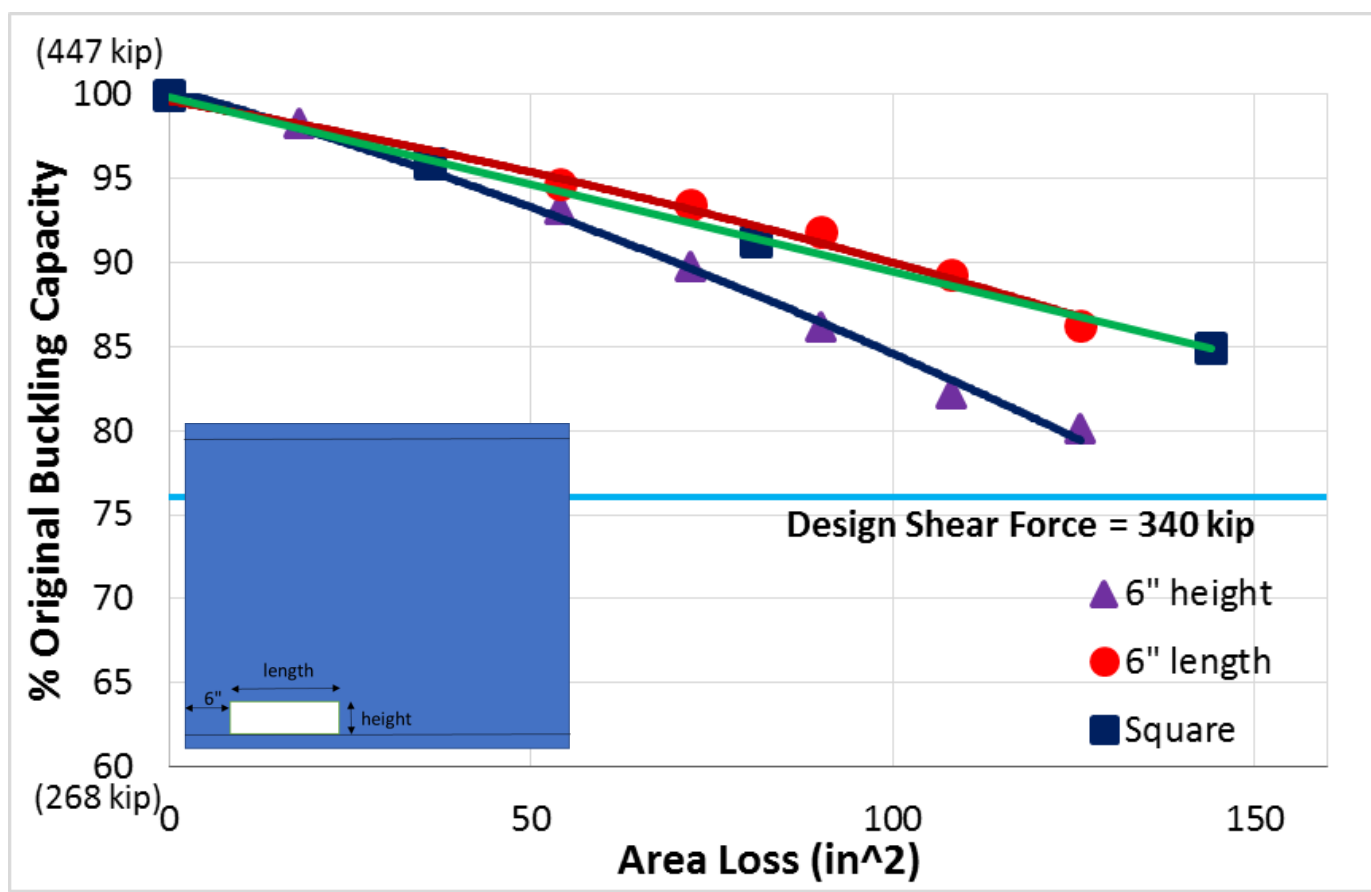

Fig. 9: Web Buckling Capacity vs. Area Loss - Shapes and Sizes.

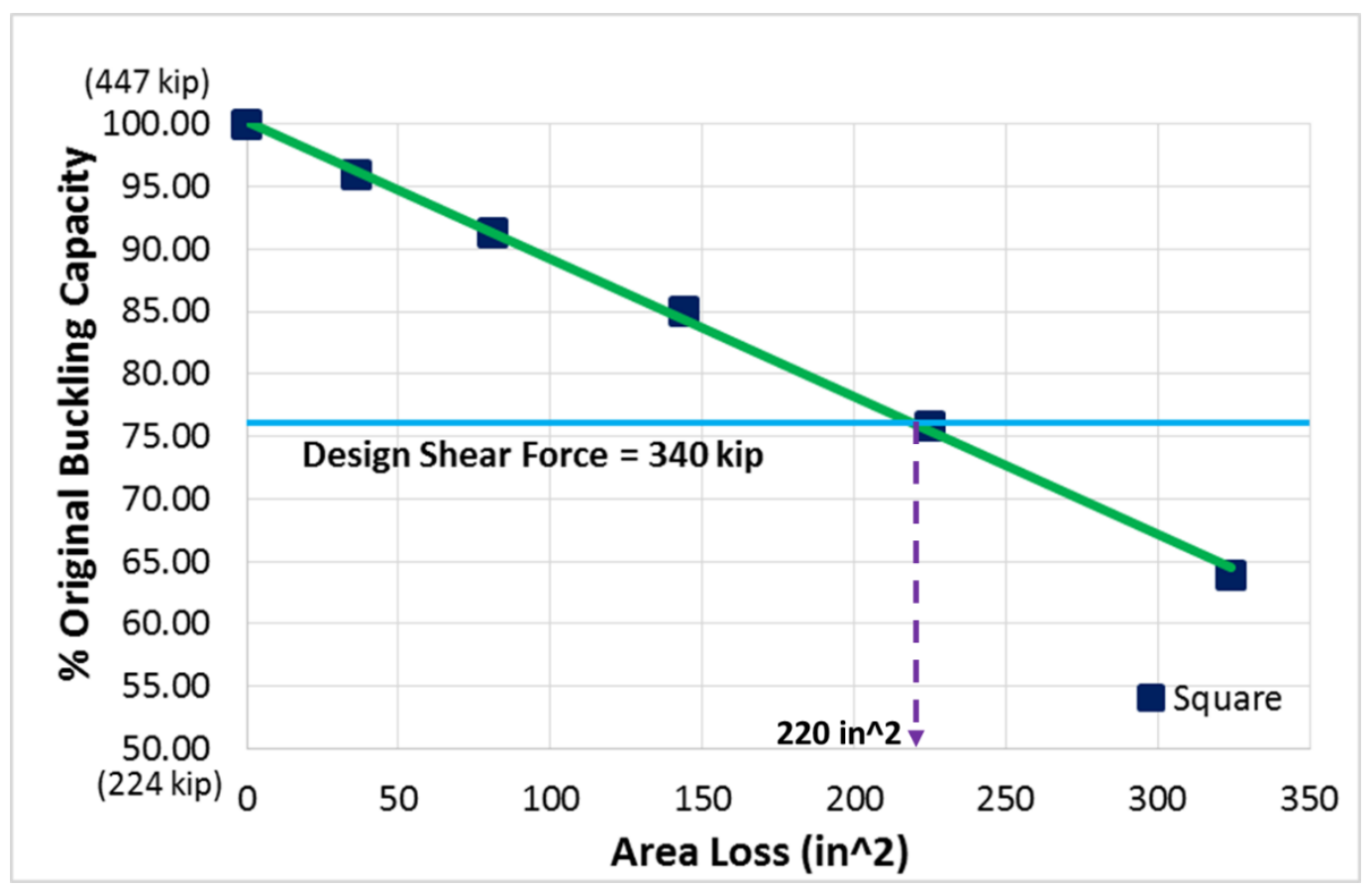

Fig. 10: Web Buckling Capacity vs. Area Loss - Square.

\section{Laboratory Testing}

In order to verify numerical modeling results, lab tests on girder models are designed and will be conducted. The models will be built on a 1:10 scale based on the real size of the girder. The girder end compression test setup is shown in Figure 11. The effects of web area loss and web thinning on the behaviors of the girder end will be investigated. The collected experimental data will include the stress-stain curve, the ultimate strength before failure, deformation measurements, and digital images of web buckling. 


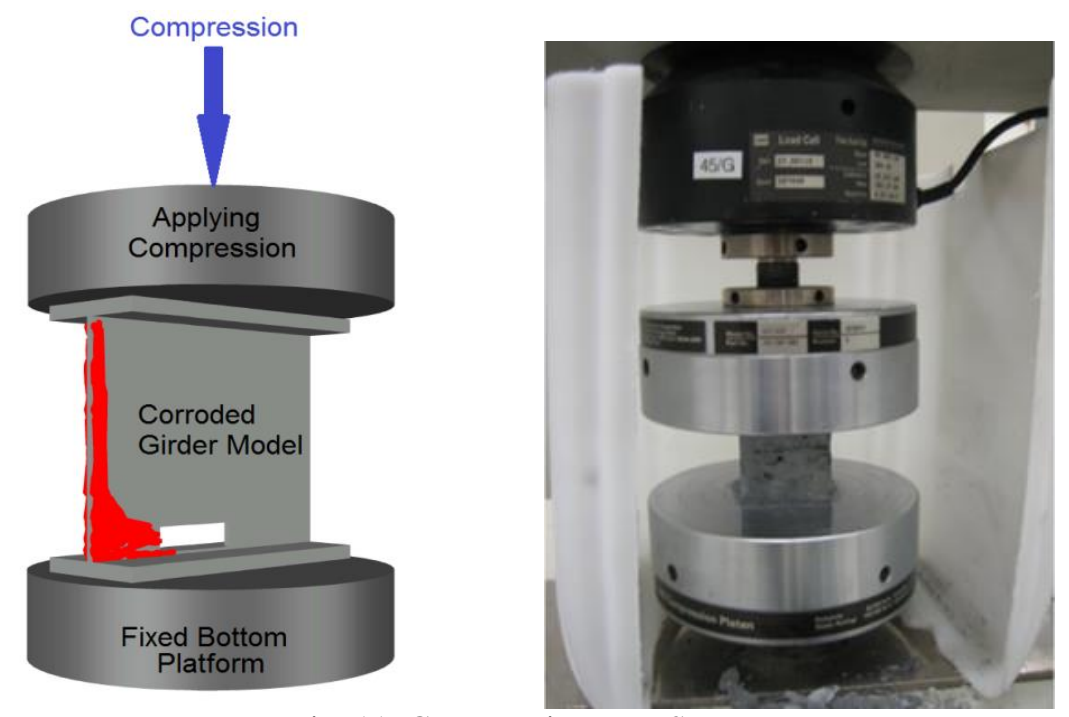

Fig. 11: Compression Test Setup.

Four types of models will be built for the corroded girder compression tests.

Model \#1: Intact steel girder model without any corrosions. This model will be used as a reference to compare with other deteriorated girder models.

Model \#2: Rusted steel girder model to simulate web thinning effect. To prepare the model, the steel girder sample will be soaked in salt water for 10 to 30 days, and the corrosion rate may be controlled by chemical detergents. To quantitatively measure the deterioration, the girder models will be sand blasted to remove structurally insignificant sections and the effective thickness will be measured with calipers.

Model \#3: Steel girder models to simulate the web area loss. Part of the web material will be removed to represent area loss. Models with different sizes, shapes and locations of area loss will be prepared and tested.

Model \#4: Rusted steel girder model with web area loss to simulate the combined effect of web thinning and area loss. This model is the closest to representing the real-world steel girder deterioration.

Laboratory testing is underway.

\section{Conclusions}

This paper is focused on the investigation of common corrosion types in steel plate girder bridges and the effects of web thinning and web area loss on the girder structural capacity due to rust.

According to the results of 3D finite element analyses, the conclusions of this study are:

1) Web thinning due to corrosion has a significant effect on girder shear and web buckling strength. Development of extensive rust can dramatically reduce the girder's structural capacity. $10 \%$ reduction in web effective thickness may result in $25 \%$ or more buckling strength loss due to decreasing effective web cross sectional area as well as increasing width to thickness ratio of the web.

2) Figure 8, Figure 9 and Figure 10 show consistently that the larger size of area loss, the lower the structural capacity. Once the size of area loss reaches a critical value, the strength may drop below the girder design load, which represents structural deficiency.

3) The shape of the area loss plays an important role in the girder's residual strength. When extending area loss in the direction parallel to the girder line, the structural capacity decreases at a significantly higher rate than extending area loss in the direction parallel to the web depth. 


\section{Acknowledgement}

This study is supported by Western New York Association for Bridge Construction and Design Research Grant (20172018) and Rochester Institute of Technology College of Applied Science and Technology Scholarship Incentive Grant (2017).

\section{References}

[1] ABAQUS/CAE, User's Guide, 2016.

[2] A. Agrawal, A. Kawaguchi, Z. Chen, "Bridge Element Deterioration Rates," Technical Report (Project \# C-01-51), The City College of New York, 2009.

[3] American Association of State Highway and Transportation Officials, "AASHTO LRFD Bridge Design Specifications", 7th ed, 2016.

[4] American Institute of Steel Construction, Steel Construction Manual.15th ed, 2017.

[5] M. S. Al Badran, "Structural Reliability Analysis of Corroded Steel Girder Bridge," M.S. Thesis, University of Nebraska-Lincoln, 2013.

[6] American Society of Civil Engineers, (ASCE), 2017 Infrastructure Report Card, 2017.

[7] M. Ghosn, B. Sivakumar, F. Miao, "Load Resistance Factor Rating (LRFR) in NYS," Technical Report, The City University of New York, 2011.

[8] J. Kayser, A. Nowak, "Reliability of Corroded Steel Girder Bridges," Elsevier Science Publishers: Structural Safety, vol. 6, 1989.

[9] J. Kulicki, Z. Prucz, D. Sorgenfrei, D. Mertz, W. Young, "Guidelines for Evaluating Corrosion Effect in Existing Steel Bridges," National Cooperative Highway Research Program, Report 333, 1990.

[10] R. Nickerson, "Performance of Weathering Steel in Highway Bridges," Technical Report, American Iron and Steel Institute, 1995.

[11] NYSDOT, Bridge Manual, 2017.

[12] M. Secer, E. T. Uzun, "Corrosion Damage Analysis of Steel Frames Considering Lateral Torsional Buckling," Izmir Katip Celebi University, Procedia Engineering, vol. 171, 2017.

[13] Y. Sharifi, "Residual Web Bearing Capacity of Corroded Steel Beams," Advanced Steel Construction, vol. 8, no. 3, pp, 242-255, 2012.

[14] J. Van de Lindt, T. Ahlborn, "Development of Steel Beam End Deterioration Guidelines," Michigan Technological University, 2005 